\title{
8-O-4'-Neolignans from Flower Buds of Magnolia fargesii and their Biological Activities
}

\author{
Xuemei Gao, ${ }^{a}$ Yanqiong Shen, ${ }^{a}$ Liying Yang, ${ }^{a, b}$ Lidang Shu, ${ }^{a}$ Ganpeng $\mathrm{Li}{ }^{*, a, b}$ and Qiu-Fen Hu${ }^{*, a}$ \\ ${ }^{a}$ Key Laboratory of Chemistry in Ethnic Medicinal Resources, State Ethnic Affairs Commission \& \\ Ministry of Education, Yunnan University of Nationalities, Kunming 650031, P. R. China \\ ${ }^{b}$ Key Laboratory of Tobacco Chemistry of Yunnan Province, Yunnan Academy of Tobacco Science, \\ Kunming 650106, P. R. China
}

\begin{abstract}
Três novos derivados de 8-O-4'-neolignanas, fargesifenols A-C, juntamente com seis neolignanas conhecidas, foram isoladas de botões de flores de Magnolia fargesii. As estruturas foram elucidadas por métodos espectroscópicos, incluindo técnicas de RMN 1D e 2D. Os compostos foram também testados quanto à sua atividade anti-HIV-1 e quanto às citotoxicidades.

Three new 8-O-4'-neolignans, fargesiphenols A-C, together with six known neolignans, were isolated from the flower buds of Magnolia fargesii. The structures were elucidated by spectroscopic methods, including extensive 1D and 2D-NMR techniques. Compounds were also tested for their anti-HIV-1 activities and cytotoxicities.
\end{abstract}

Keywords: Magnolia fargesii, 8-O-4'-neolignans, anti-HIV-1 activity, cytotoxicity

\section{Introduction}

The genus of Magnolia (Magnoliaceae) has traditionally been used as herb medicine in China for a long time. Especially, Xinyi (dried flower buds of Magnolia fargesii), has been used for the treatment of inflammatory-related diseases such as nasal congestion, empyema, sinusitis, and allergic rhinitis. ${ }^{1,2}$ Previous phytochemical investigations have reported that this species contains several secondary metabolites such as lignans, ${ }^{3-5}$ neolignans, ${ }^{6,7}$ sesquiterpenes, ${ }^{2,8}$ and essential oils, ${ }^{9}$ which show various biological activities.

To search for more new bioactive compounds from this plant, we reexamined the flower buds of $M$. fargesii, which led to the isolation of three new 8-O-4'-neolignans, named fargesiphenols A-C (1-3), along with six known compounds (4-9). In addition, the anti-HIV-1 activities and their cytotoxicities were evaluated. Their structure elucidation and biological activities are described in this paper.

\section{Results and Discussion}

A $70 \%$ aq. acetone extract prepared from the flower buds of M. fargesii was partitioned between EtOAc and

*e-mail:huqiufena@yahoo.com,ganpeng_li@sina.com
$\mathrm{H}_{2} \mathrm{O}$. The EtOAc layer was subjected repeatedly to column chromatography on Si gel, Sephadex LH-20, RP-18 and preparative HPLC to afford compounds 1-9, including three new 8-O-4'-neolignans named fargesiphenols A-C (1-3), together with six known neolignans, polysyphorin (4), ${ }^{10}$ virolin (5), ${ }^{11} 7 S, 8 S$-threo-4,7,9,9'tetrahydroxy-3, 3'-dimethoxy-8-O-4' -neolignan (6), ${ }^{12}$ 7S,8R-erythro- 4,7,9,9'-tetrahydroxy-3,3'-dimethoxy-8- $O$ 4'-neolignan (7), ${ }^{12}$ (7R,8S)-1-(3,4-dimethoxyphenyl)-2-[4(3-hydroxy-1-propenyl)-methoxy-phenoxy]-propane-1,3diol (8), ${ }^{13}$ and rhaphidecursinol A (9).${ }^{10}$ The structures of compounds 1-9 are shown in Figure 1, and the ${ }^{1} \mathrm{H}$ and ${ }^{13} \mathrm{C}$ NMR data of compounds 1-3 are listed in Table 1.

Compound 1 was obtained as pale yellow gum. Its molecular formula was determined as $\mathrm{C}_{21} \mathrm{H}_{26} \mathrm{O}_{6}$ from the HRESIMS quasi-molecular ion peak $[\mathrm{M}+\mathrm{Na}]^{+}$at $m / z, 397.1622$ (calc. 397.1627). Its ${ }^{1} \mathrm{H}$ and ${ }^{13} \mathrm{C}$ NMR spectra showed signals of 26 hydrogens and 21 carbons, respectively, corresponding to two aromatic rings with five aromatic protons $\left(\delta_{\mathrm{H}} 6.99,7.34,7.09,7.15,6.98\right)$, two methyl groups $\left(\delta_{\mathrm{C}} 14.5,18.4\right)$, three methoxyl groups $\left(\delta_{\mathrm{C}} 55.9,55.9,60.4\right)$, two oxidated methine groups $\left(\delta_{\mathrm{C}} 75.1,80.9\right)$, one allyl group $\left(\delta_{\mathrm{C}} 131.4,124.1,18.4 ; \delta_{\mathrm{H}}\right.$ $6.38 \mathrm{~d} J 15.8,6.10-6.17 \mathrm{~m}, 1.75 \mathrm{~d} J 6.5)$, and a phenolic hydroxyl group $\left(\delta_{\mathrm{H}} 11.25\right)$. Strong absorption bands accounting for hydroxyl $\left(3498 \mathrm{~cm}^{-1}\right)$ and aromatic groups 
<smiles>[R]c1cc([C@H](O)C(C)Oc2c([R])cc(/C=C/C)cc2OC)cc(OC)c1OC</smiles>

$1 \mathrm{R}^{1}=\mathrm{OH}, \mathrm{R}^{2}=\mathrm{H}$

$2 \mathrm{R}^{1}=\mathrm{OH}, \mathrm{R}^{2}=\mathrm{OMe}$

$3 \mathrm{R}^{1}=\mathrm{OAc}, \mathrm{R}^{2}=\mathrm{OMe}$<smiles>C/C=C/c1ccc(O[C@H](C)[C@H](O)c2ccc(OC)c(OC)c2)c(OC)c1</smiles>

5<smiles>C/C=C/c1cc(OC)c(O[C@H](C)[C@H](O)c2cc(OC)c(OC)c(OC)c2)c(OC)c1</smiles>

4<smiles>COc1cc([C@@H](O)[C@H](CO)Oc2ccc(CCCO)cc2)ccc1O</smiles>

6<smiles>C=CCc1cc(OC)c(O[C@@H](C)[C@H](O)c2cc(OC)c(OC)c(OC)c2)c(OC)c1</smiles>

Figure 1. The structures of 8-O-4'-neolignans from Magnolia fargesii.

$\left(1608,1520,1478 \mathrm{~cm}^{-1}\right)$ could also be observed in its IR spectrum. The UV spectrum of $\mathbf{1}$ showed absorption maxima at 285 and $210 \mathrm{~nm}$, which confirmed the existence of the aromatic functions. The ${ }^{1} \mathrm{H}-{ }^{1} \mathrm{H}$ COSY correlations H-7/H-8/H-9, H-7'/H-8'/H-9', together with HMBC correlations (Figure 2$)$ of $\mathrm{H}-7\left(\delta_{\mathrm{H}} 5.38\right)$ with C-8 $\left(\delta_{\mathrm{C}} 80.9\right)$, $\mathrm{C}-9\left(\delta_{\mathrm{C}} 14.5\right), \mathrm{C}-1\left(\delta_{\mathrm{C}} 139.5\right), \mathrm{C}-2\left(\delta_{\mathrm{C}} 102.9\right)$ and C-6 $\left(\delta_{\mathrm{C}}\right.$ $109.0)$, of H-7' $\left(\delta_{\mathrm{H}} 6.38\right)$ with C-2' $\left(\delta_{\mathrm{C}} 110.7\right), \mathrm{C}-1$ ' $\left(\delta_{\mathrm{C}}\right.$ $132.6)$ and $\mathrm{C}-6$ ' $\left(\delta_{\mathrm{C}} 119.3\right)$, and $\mathrm{H}-8\left(\delta_{\mathrm{C}} 4.88\right)$ with $\mathrm{C}-1\left(\delta_{\mathrm{C}}\right.$ $139.5)$ and $\mathrm{C}-4$ ' $\left(\delta_{\mathrm{C}} 147.4\right)$, suggested that 1 is a $8-O-4$ 'neolignan possessing three methoxyl groups and a phenolic hydroxyl group. ${ }^{14}$

Three methoxyl groups located at C-3, C-4, C-3' were assigned from the HMBC correlations of the methoxyl proton signals $\left(\delta_{\mathrm{H}} 3.77,3.88,3.74\right)$ with $\mathrm{C}-3\left(\delta_{\mathrm{C}} 153.9\right)$, C-4 $\left(\delta_{\mathrm{C}} 136.7\right)$, and C-3' $\left(\delta_{\mathrm{C}} 151.9\right)$, respectively. The presence of a phenolic hydroxyl group at C-5 was supported by the HMBC correlations of the phenolic hydroxyl proton signal $\left(\delta_{\mathrm{H}} 11.25\right)$ with $\mathrm{C}-4\left(\delta_{\mathrm{C}} 136.7\right), \mathrm{C}-5\left(\delta_{\mathrm{C}} 151.9\right)$, and C-6 $\left(\delta_{\mathrm{C}} 109.0\right)$, respectively. Thus, the plain structure of 1 was established.
The configuration of the two chiral carbons (C-7 and C-8) was considered to be threo according to the coupling constant $(\mathrm{J} 7.2 \mathrm{~Hz})$ between $\mathrm{H}-7$ and $\mathrm{H}-8,{ }^{15}$ which is distinct from that of the erythro diastereoisomers..$^{16,17}$ The absolute configurations at C-7 and C-8 of $\mathbf{1}$ could be established on the basis of ROESY and CD spectroscopic evidence. ${ }^{18}$ The CD spectrum of 1 gave a positive cotton effect at $237 \mathrm{~nm}$, and clear ROESY correlations observed between $\mathrm{H}-7$ and H-8, H-7 and H-2, H-7 and $\mathrm{H}_{3}-9$ (Figure 3) indicated the 7S, $8 S$-configuration of $\mathbf{1}$, which was named fargesiphenol A.

Compounds $\mathbf{2}$ and $\mathbf{3}$ (fargesiphenols B and C) were all obtained as yellow gums. HRESIMS analysis of $\mathbf{2}$ demonstrated that it has the molecular formula $\mathrm{C}_{22} \mathrm{H}_{28} \mathrm{O}_{7}$ $\left(\mathrm{m} / z\right.$ 427.1730, for $[\mathrm{M}+\mathrm{Na}]^{+}$, calc. 427.1733). The NMR spectra of $\mathbf{2}$, when compared to those of $\mathbf{1}$, displayed an additional methoxy group $\left(\delta_{\mathrm{H}} 3.85 ; \delta_{\mathrm{C}} 55.6\right)$, which was located at C-5' from the HMBC cross-peak between this carbon $\left(\delta_{\mathrm{C}} 152.3\right)$ and the methoxyl protons $\left(\delta_{\mathrm{C}} 3.85\right)$.

The NMR spectra of $\mathbf{3}$, when compared to those of $\mathbf{2}$, displayed the characteristic signals of an acetoxy group $\left(\delta_{\mathrm{H}} 2.19, \delta_{\mathrm{C}} 21.1\right.$ and $\left.\delta_{\mathrm{C}} 169.9\right)$. Its ${ }^{13} \mathrm{C}$ NMR spectrum 
Table 1. ${ }^{1} \mathrm{H}$ and ${ }^{13} \mathrm{C}$ NMR Data (in $\mathrm{C}_{5} \mathrm{D}_{5} \mathrm{~N}$ ) of compounds 1-3

\begin{tabular}{|c|c|c|c|c|c|c|}
\hline \multirow{2}{*}{ position } & \multicolumn{2}{|c|}{1} & \multicolumn{2}{|c|}{2} & \multicolumn{2}{|c|}{3} \\
\hline & $\delta_{\mathrm{C}}(\mathrm{m})$ & $\delta_{\mathrm{H}}(\mathrm{m}, J / \mathrm{Hz})$ & $\delta_{\mathrm{C}}(\mathrm{m})$ & $\delta_{\mathrm{H}}(\mathrm{m}, J / \mathrm{Hz})$ & $\delta_{\mathrm{C}}(\mathrm{m})$ & $\delta_{\mathrm{H}}(\mathrm{m}, J / \mathrm{Hz})$ \\
\hline 1 & $139.5(\mathrm{~s})$ & & $139.4(\mathrm{~s})$ & & $138.5(\mathrm{~s})$ & \\
\hline 2 & $102.9(\mathrm{~d})$ & $6.99(\mathrm{~s})$ & $102.8(\mathrm{~d})$ & $6.91(\mathrm{~s})$ & $107.2(d)$ & $7.03(\mathrm{~s})$ \\
\hline 3 & $153.9(\mathrm{~s})$ & & $153.5(\mathrm{~s})$ & & $152.7(\mathrm{~s})$ & \\
\hline 4 & $136.7(\mathrm{~s})$ & & $137.0(\mathrm{~s})$ & & $142.1(\mathrm{~s})$ & \\
\hline 5 & $151.9(\mathrm{~s})$ & & $151.2(\mathrm{~s})$ & & $144.8(\mathrm{~s})$ & \\
\hline 6 & $109.0(\mathrm{~d})$ & $7.34(\mathrm{~s})$ & $108.9(\mathrm{~d})$ & $7.34(\mathrm{~s})$ & $111.4(d)$ & $7.49(\mathrm{~s})$ \\
\hline 7 & 75.1 (d) & $5.38(\mathrm{~d}, J 7.2)$ & $75.0(\mathrm{~d})$ & $5.35(\mathrm{~d}, J 7.2)$ & $75.8(\mathrm{~d})$ & $5.51(\mathrm{~d}, J 7.2)$ \\
\hline 8 & 80.9 (d) & $4.88(\mathrm{~m})$ & $80.9(\mathrm{~d})$ & $4.90(\mathrm{~m})$ & $80.4(d)$ & $4.97(\mathrm{~m})$ \\
\hline 9 & $14.5(q)$ & $1.55(\mathrm{~d}, J 5.9)$ & $14.5(\mathrm{q})$ & $1.54(\mathrm{~d}, J 5.9)$ & $14.8(\mathrm{q})$ & $1.55(\mathrm{~d}, J 5.8)$ \\
\hline 1 ' & $132.6(\mathrm{~s})$ & & $133.3(\mathrm{~s})$ & & $133.8(\mathrm{~s})$ & \\
\hline 2 ' & $110.7(d)$ & $7.09(\mathrm{~s})$ & $104.2(d)$ & $6.59(\mathrm{~s})$ & $103.4(d)$ & $6.56(\mathrm{~s})$ \\
\hline 3 ' & $151.9(\mathrm{~s})$ & & $152.3(\mathrm{~s})$ & & $151.2(\mathrm{~s})$ & \\
\hline $4^{\prime}$ & $147.4(\mathrm{~s})$ & & $136.5(\mathrm{~s})$ & & $136.9(\mathrm{~s})$ & \\
\hline 5, & $117.8(\mathrm{~d})$ & $6.98(\mathrm{~d}, J 8.2)$ & $152.3(\mathrm{~s})$ & & $151.2(\mathrm{~s})$ & \\
\hline $6{ }^{\prime}$ & $119.3(d)$ & $7.15(\mathrm{~d}, J 8.2)$ & 104.2 (d) & $6.59(\mathrm{~s})$ & $103.4(d)$ & $6.56(\mathrm{~s})$ \\
\hline $7^{\prime}$ & $131.4(\mathrm{~d})$ & $6.38(\mathrm{~d}, J 15.8)$ & $131.6(d)$ & $6.34(\mathrm{~d}, J 15.9)$ & $133.1(\mathrm{~d})$ & $6.41(\mathrm{~d}, J 16.2)$ \\
\hline 8, & $124.1(\mathrm{~d})$ & $6.10-6.17(\mathrm{~m})$ & $124.2(\mathrm{~d})$ & $6.13-6.16(\mathrm{~m})$ & $124.8(\mathrm{~d})$ & $6.02-6.05(\mathrm{~m})$ \\
\hline 9' & $18.4(q)$ & $1.75(\mathrm{~d}, J 6.5)$ & $18.5(q)$ & $1.74(\mathrm{~d}, J 6.5)$ & $18.7(q)$ & $1.80(\mathrm{~d}, J 6.6)$ \\
\hline OMe-3 & $55.9(\mathrm{q})$ & $3.77(\mathrm{~s})$ & $55.9(\mathrm{q})$ & $3.80(\mathrm{~s})$ & $55.9(\mathrm{q})$ & $3.82(\mathrm{~s})$ \\
\hline OMe-4 & $60.4(q)$ & $3.88(\mathrm{~s})$ & $60.8(q)$ & $3.81(\mathrm{~s})$ & $60.9(q)$ & $3.85(\mathrm{~s})$ \\
\hline OMe-2' & $55.9(\mathrm{q})$ & $3.74(\mathrm{~s})$ & $55.6(q)$ & $3.85(\mathrm{~s})$ & $55.8(\mathrm{q})$ & $3.95(\mathrm{~s})$ \\
\hline OMe-6' & & & $55.6(q)$ & $3.85(\mathrm{~s})$ & $55.8(\mathrm{q})$ & $3.95(\mathrm{~s})$ \\
\hline$-\mathrm{OAc}$ & & & & & $21.1(\mathrm{q}) 169.9(\mathrm{~s})$ & $2.19(\mathrm{~s})$ \\
\hline
\end{tabular}

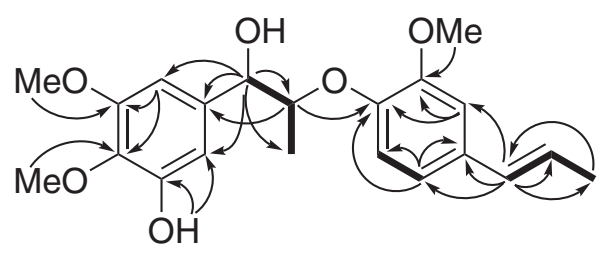

Figure 2. Selected $\mathrm{HMBC}(\mathrm{H} \rightarrow \mathrm{C})$ and ${ }^{1} \mathrm{H}-{ }^{1} \mathrm{H}$ COSY $(-)$ correlations of $\mathbf{1}$.

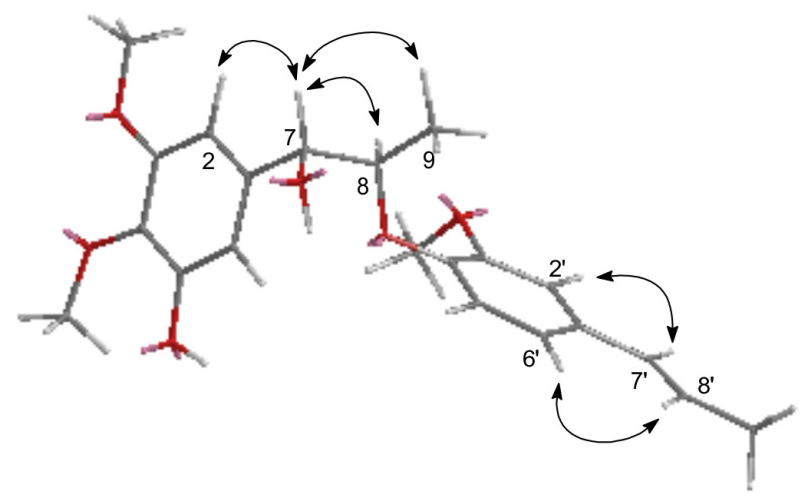

Figure 3. Key ROESY $(\curvearrowleft)$ correlations of $\mathbf{1}$.

showed downfield-shifted signals for C-4 $\left(\delta_{\mathrm{C}}\right.$ 142.1) and C-6 $\left(\delta_{\mathrm{C}} 111.4\right)$, and an upfield-shifted signal for C-5 $\left(\delta_{\mathrm{C}} 144.8\right)$, thus corroborating the placement of the acetoxy group at C-5. According to the observed ROESY correlations and comparison of ${ }^{1} \mathrm{H}$ and ${ }^{13} \mathrm{C}$ NMR data with those of $\mathbf{1}$ (Table 1), the relative configurations of $\mathbf{2}$ and $\mathbf{3}$ were established as being the same as that of $\mathbf{1}$. The configuration of the two chiral carbons (C-7 and C-8) for 2 and $\mathbf{3}$ was considered to be threo according to the coupling constant $(J 7.2 \mathrm{~Hz})$ between $\mathrm{H}-7$ and $\mathrm{H}-8$, and a positive cotton effect at $237 \mathrm{~nm}$ for $\mathbf{2}$, and $238 \mathrm{~nm}$ for $\mathbf{3}$ in their $\mathrm{CD}$ spectrum indicated a $7 S, 8 S$-configuration. ${ }^{15}$

Since some neolignans are reported to possess anti-HIV activities, ${ }^{19,20}$ these have been tested for compounds 1-9. The cytotoxicity assay against $\mathrm{C} 8166$ cells $\left(\mathrm{CC}_{50}\right)$, and antiHIV-1 activity were evaluated by the inhibition assay for the cytopathic effects of HIV-1 $\left(\mathrm{EC}_{50}\right)$, using azidothymidine (AZT) as a positive control $\left(\mathrm{EC}_{50}=0.034 \mu \mathrm{g} \mathrm{mL}^{-1}\right.$ and $\mathrm{CC}_{50}=200 \mu \mathrm{g} \mathrm{mL}^{-1}$ ). ${ }^{21}$ The results (Table 2) revealed significant activity for compounds $\mathbf{2}, \mathbf{6}, \mathbf{7}$, and $\mathbf{8}$, with therapeutic index (TI) values above 30 . Compounds $\mathbf{1}, \mathbf{4}$, and $\mathbf{9}$ showed moderate activity with TI values above 10 .

Some neolignans are also reported to possess cytotoxic activities, ${ }^{22,23}$ which led us to evaluate compounds 1-9 for their cytotoxicities. The cytotoxicity tests were performed in triplicate using a previously reported procedure. ${ }^{24} \mathrm{In}$ the 3-(4,5-dimethylthiazol-2-yl)-2,5- diphenyltetrazolium bromide (MTT) assay, the $\mathrm{IC}_{50}$ was defined as the concentration of the tested compound resulting in a $50 \%$ 
Table 2. Anti-HIV activities of the compounds 1-9

\begin{tabular}{lccc}
\hline Compound & $\mathrm{CC}_{50} /\left(\mu \mathrm{gL}^{-1}\right)$ & $\mathrm{EC}_{50} /\left(\mu \mathrm{g} \mathrm{mL}^{-1}\right)$ & $\mathrm{TI}^{\mathrm{a}}$ \\
\hline $\mathbf{1}$ & 63.5 & 3.62 & 17.5 \\
$\mathbf{2}$ & $\geq 200$ & 4.86 & $\geq 41.2$ \\
$\mathbf{3}$ & 28.6 & 3.11 & 9.20 \\
$\mathbf{4}$ & 22.6 & 2.16 & 10.5 \\
$\mathbf{5}$ & 61.5 & 6.87 & 8.95 \\
$\mathbf{6}$ & 135.6 & 3.87 & 35.0 \\
$\mathbf{7}$ & 185.4 & 5.54 & 33.5 \\
$\mathbf{8}$ & $\geq 200$ & 2.08 & $\geq 96.2$ \\
$\mathbf{9}$ & 87.9 & 3.09 & 28.4 \\
\hline${ }^{\mathrm{a}} \mathrm{TI}=\mathrm{EC}_{50} / \mathrm{CC}_{50}$. & & &
\end{tabular}

reduction of absorbance compared with untreated cells. The cytotoxic activities against HL-60, Hep-G2, KB, and MDA-MB-231 tumor cell lines by MTT-assay (with camptothecin as the positive control) are shown in Table 3. Compound 2 revealed high cytotoxic activity to HL-60 and MDA-MB-231 cells, whereas compound 8 showed high cytotoxic activity to $\mathrm{KB}$ cells, both with $\mathrm{IC}_{50}$ values close to those of positive control. The other compounds displayed moderate or weak cytotoxic activity.

Table 3. Cytotoxicities of compounds 1-9

\begin{tabular}{lcccc}
\hline \multirow{2}{*}{ Compounds } & \multicolumn{4}{c}{ Cell lines } \\
\cline { 2 - 5 } & HL-60 & HepG2 & KB & MDA-MB-231 \\
\cline { 2 - 5 } $\mathrm{IC}_{50} /\left(\mu \mathrm{mol} \mathrm{L}{ }^{-1}\right)$ \\
$\mathbf{1}$ & 12.0 & 6.08 & 9.21 & 6.48 \\
$\mathbf{3}$ & 1.69 & 3.50 & 2.05 & 2.19 \\
$\mathbf{4}$ & 10.3 & 6.50 & 8.55 & 7.19 \\
$\mathbf{5}$ & 5.28 & 11.4 & 14.4 & 6.25 \\
$\mathbf{6}$ & 7.01 & 6.42 & 15.7 & 6.15 \\
$\mathbf{7}$ & 11.0 & 8.58 & 9.59 & 8.23 \\
$\mathbf{8}$ & 8.17 & 6.29 & 7.51 & 10.3 \\
$\mathbf{9}$ & 16.2 & 7.50 & 1.76 & 4.02 \\
Camptothecin & 1.95 & 0.98 & 1.69 & 18.1 \\
\hline
\end{tabular}

For a compound to be deemed effective, an $\mathrm{IC}_{50}$ value $<100 \mu \mathrm{mol} \mathrm{L}^{-1}$ is required. Camptothecin was used as positive control. HL-60, human acute promyelocytic leukemia; Hep-G2, human hepatocellular carcinoma; KB, human oropharyngeal epidermoid carcinoma; MDA-MB-231, human breast cancer cells.

\section{Experimental}

\section{General experimental procedures}

Optical rotations were measured with a Horiba SEPA-300 polarimeter. UV spectra were obtained using a Shimadzu UV-2401A spectrophotometer. A Tenor 27 spectrophotometer was used for scanning IR spectra with $\mathrm{KBr}$ pellets. CD spectra were measured on a JASCO J-810 spectropolarimeter. 1D and 2D NMR spectra were recorded on DRX-500 spectrometers with TMS as internal standard. HRESIMS was performed on an API QSTAR time-offlight spectrometer and a VG Autospec-3000 spectrometer, respectively. Preparative HPLC was performed on a Shimadzu LC-8A preparative liquid chromatograph with a ZORBAX PrepHT GF $(21.2 \mathrm{~mm} \times 25 \mathrm{~cm}, 7 \mu \mathrm{m})$ column or a Venusil MP $_{18}(20 \mathrm{~mm} \times 25 \mathrm{~cm}, 5 \mu \mathrm{m})$ column. Column chromatography was performed with Si gel (200-300 mesh, Qing-dao Marine Chemical, Inc., Qingdao, China), Lichroprep RP-18 gel (40-63 $\mu$ m, Merck, Darmstadt, Germany) and MCI gel (75-150 $\mu \mathrm{m}$, Mitsubishi Chemical Corporation, Tokyo, Japan). The fractions were monitored by TLC, and spots were visualized by heating Si gel plates sprayed with $5 \% \mathrm{H}_{2} \mathrm{SO}_{4}$ in $\mathrm{EtOH}$.

\section{Plant material}

The flower buds of M. fargesii, indigenous to Nanzhao country, Henang province, were purchased from Kunming Herb Medicine Market in September 2010. A voucher specimen (YNNI-10-9-28) has been deposited in our laboratory.

\section{Extraction and isolation}

The air-dried and powdered flower buds of Magnolia fargesii $(4.5 \mathrm{~kg})$ were extracted four times with $70 \%$ aqueous acetone $(4 \times 3 \mathrm{~L})$ at room temperature, filtered, and the filtrate evaporated under reduced pressure and partitioned with EtOAc $(4 \times 3 \mathrm{~L})$. The EtOAc phase (212 g) was applied to silica gel (200-300 mesh) column chromatography, eluting with a $\mathrm{CHCl}_{3}-\mathrm{MeOH}$ gradient system (20:1, 9:1, 8:2, 7:3, 6:4, 5:5), to give six fractions A-F. Further separation of fraction B $(35.8 \mathrm{~g})$ by silica gel column chromatography, eluted with $\mathrm{CHCl}_{3}$-acetone (9:1-2:1), yielded mixtures B1-B6. Fraction B2 (8:2, $4.8 \mathrm{~g})$ was subjected to silica gel column chromatography using petroleum ether-acetone, and semi-preparative HPLC (55\% $\mathrm{MeOH}-\mathrm{H}_{2} \mathrm{O}$, flow rate $\left.12 \mathrm{~mL} \mathrm{~min}{ }^{-1}\right)$ to give $\mathbf{3}(22.6 \mathrm{mg})$, $\mathbf{4}(18.9 \mathrm{mg}), \mathbf{5}(22.7 \mathrm{mg})$ and $\mathbf{9}(28.5 \mathrm{mg})$. Fraction B3 (7:3, $5.47 \mathrm{~g}$ ) was subjected to silica gel column chromatography using $\mathrm{CHCl}_{3}$-acetone, and semi-preparative HPLC (48\% $\mathrm{MeOH}-\mathrm{H}_{2} \mathrm{O}$, flow rate $\left.12 \mathrm{~mL} \mathrm{~min}{ }^{-1}\right)$ to give $\mathbf{1}(11.6 \mathrm{mg}$ ) and $2(28.9 \mathrm{mg})$. Fraction B4 (7:3, $3.28 \mathrm{~g})$ was subjected to silica gel column chromatography using $\mathrm{CHCl}_{3}$-acetone, and semi-preparative HPLC $\left(40 \% \mathrm{MeOH}-\mathrm{H}_{2} \mathrm{O}\right.$, flow rate $\left.12 \mathrm{~mL} \mathrm{~min}^{-1}\right)$ to give $3(14.2 \mathrm{mg}), \mathbf{6}(22.5 \mathrm{mg})$, and 7 (18.2 mg). 
Anti-HIV-1 assay

The cytotoxicity assay against $\mathrm{C} 8166$ cells $\left(\mathrm{CC}_{50}\right)$ was assessed using the MTT method, and anti-HIV-1 activity was evaluated by the inhibition assay for the cytopathic effects of HIV-1 $\left(\mathrm{EC}_{50}\right) \cdot{ }^{21}$

\section{Cytotoxicity assay}

The cytotoxicity tests for these compounds were performed against HL-60, Hep-G2, KB, and MDA-MB-231 tumor cell lines by the MTT-assay using camptothecin as positive control. ${ }^{24}$

\section{Fargesiphenol A (1)}

Pale yellow gum; $[\alpha]_{\mathrm{D}}^{24.2}+38.5(c 0.20, \mathrm{MeOH})$; $\mathrm{CD}$ (c $0.05, \mathrm{MeOH}): \Delta \varepsilon_{220 \mathrm{~nm}}+0.36, \Delta \varepsilon_{237 \mathrm{~mm}}+7.18, \Delta \varepsilon_{280 \mathrm{~nm}}$ $-0.97, \Delta \varepsilon_{320 \mathrm{~nm}}-0.21 ; \mathrm{UV}(\mathrm{MeOH}) \lambda_{\max }(\log \varepsilon) 320(2.82)$, 285 (3.78), $210(4.27) \mathrm{nm}$; IR (KBr) $v_{\max } / \mathrm{cm}^{-1}: 3498$, 2957, 2874, 1608, 1520, 1478, 1440, 1265, 958; ${ }^{1} \mathrm{H}$ NMR (500 MHz) and ${ }^{13} \mathrm{C} \mathrm{NMR} \mathrm{(125} \mathrm{MHz)} \mathrm{data,} \mathrm{Table} \mathrm{1;} \mathrm{positive}$ ESIMS m/z 397 [M+Na] ; HRESIMS m/z 397.1622 $[\mathrm{M}+\mathrm{Na}]^{+}\left(\right.$calc. $\mathrm{C}_{21} \mathrm{H}_{26} \mathrm{NaO}_{6}$ for 397.1627).

\section{Fargesiphenol B (2)}

Yellow gum; $[\alpha]_{D}^{24.0}+41.2(c 0.22, \mathrm{MeOH}) ; \mathrm{CD}(c 0.05$, $\mathrm{MeOH}): \Delta \varepsilon_{220 \mathrm{~nm}}+1.28, \Delta \varepsilon_{237 \mathrm{~nm}}+14.6, \Delta \varepsilon_{280 \mathrm{~nm}}-2.18$, $\Delta \varepsilon_{320 \mathrm{~nm}}-0.96$; UV (MeOH) $\lambda_{\text {max }}(\log \varepsilon) 320$ (2.88), 282 (3.82), $210(4.23) \mathrm{nm}$; IR (KBr) $v_{\max } / \mathrm{cm}^{-1}: 3495,2959$, 2873, 1608, 1524, 1486, 1437, 1263, 954; ${ }^{1} \mathrm{H}$ NMR (500 MHz) and ${ }^{13} \mathrm{C}$ NMR (125 MHz) data, Table 1; positive ESIMS $m / z 427[\mathrm{M}+\mathrm{Na}]^{+}$; HRESIMS $m / z, 427.1730$ $[\mathrm{M}+\mathrm{Na}]^{+}\left(\right.$calc. $\mathrm{C}_{22} \mathrm{H}_{28} \mathrm{NaO}_{7}$ for 427.1733$)$.

\section{Fargesiphenol C (3)}

Yellow gum; $[\alpha]_{\mathrm{D}}^{24.5}+42.5(c 0.22, \mathrm{MeOH}) ; \mathrm{CD}(c 0.05$, $\mathrm{MeOH}): \Delta \varepsilon_{220 \mathrm{~nm}}+0.47, \Delta \varepsilon_{238 \mathrm{~nm}}+6.52, \Delta \varepsilon_{280 \mathrm{~nm}}-0.83$, $\Delta \varepsilon_{320 \mathrm{~nm}}-0.49$; UV (MeOH) $\lambda_{\text {max }}(\log \varepsilon) 318$ (2.89), 280 (3.86), $210(4.20) \mathrm{nm}$; IR (KBr) $v_{\max } / \mathrm{cm}^{-1}: 3493,2950$, 2876, 1614, 1529, 1482, 1442, 1260, 959; ${ }^{1} \mathrm{H}$ NMR $(500 \mathrm{MHz})$ and ${ }^{13} \mathrm{C}$ NMR (125 MHz) data, Table 1; positive ESIMS $m / z, 469[\mathrm{M}+\mathrm{Na}]^{+}$; HRESIMS $m / z, 469.1833$ $[\mathrm{M}+\mathrm{Na}]^{+}\left(\right.$calc. $\mathrm{C}_{24} \mathrm{H}_{30} \mathrm{NaO}_{8}$ for 469.1838$)$.

\section{Supplementary Information}

${ }^{13} \mathrm{C}$ NMR, DEPT, ${ }^{1} \mathrm{H}$ NMR, HSQC, HMBC, ${ }^{1} \mathrm{H}-{ }^{1} \mathrm{H}$ COSY, ROESY, CD, and HRESIMS spectra of fargesiphenol A; ${ }^{13} \mathrm{C}$ NMR, DEPT, ${ }^{1} \mathrm{H}$ NMR, HSQC, HMBC, and CD spectra of fargesiphenol B and C, are available free of charge at http://jbcs.sbq.org.br as PDF file.

\section{Acknowledgments}

This project was supported financially by the Excellent Scientific and Technological Team of Yunnan High School (2010CI08), and Green Chemistry and Functional Materials Research for Yunnan Innovation Team (2011HC008).

\section{References}

1. Miyazawa, M.; Kasahara, H.; Kameoka, H.; Phytochemistry 1992, 31, 3666.

2. Lee, Y. J.; Lee, Y. M.; Lee, C. K.; Jung, J. K.; Han, S. B.; Hong, J. T.; Pharmacol. Ther. 2011, 130, 157.

3. Huang, Y. L.; Chen, C. C.; Chen, Y. P.; Hsu, H. Y.; Kuo, Y. H.; Planta Med. 1990, 56, 237.

4. Miyazawa, M.; Ishikawa, Y.; Kasahara, H.; Yamanaka, J.; Kameoka, H.; Phytochemistry 1994, 35, 611.

5. Lee, J.; Lee, D.; Jang, D. S.; Nam, J. W.; Kim, J. P.; Park, K. H.; Yang, M. S.; Seo, E. K.; Chem. Pharm. Bull. 2007, 55, 137.

6. Lee, J.; Seo, E. K.; Jang, D. S.; Ha, T. J.; Kim, J. P.; Nam, J. W.; Bae, G.; Kim, J. S.; Chem. Pharm. Bull. 2009, 57, 298.

7. Kelm, M. A.; Nair, M. G.; Stud. Nat. Prod. Chem. 2000, 24 , 845.

8. Jung, K. Y.; Kim, D. S.; Park, S. H.; Lee, I. S.; Oh, S. R.; Lee, J. J.; Kim, E. H.; Lee, H. K.; Phytochemistry 1998, 48, 1383.

9. Fang, J. Y.; Tsai, T. H.; Hung, C. F.; Wong, W. W.; J. Pharm. Pharmacol. 2004, 56, 1493.

10. Zhang, H. J.; Tamez, P. A.; Vu, D. H.; Ghee, T. T.; Nguyen, V. H.; Le, T. X.; Le, M. H.; Nguyen. M. C.; Do, T. T.; Soejarto, D. D.; Fong, H. H.; Pezzuto, J. M.; J. Nat. Prod. 2001, 64, 772.

11. Barata, L. E.; Santos, L. S.; Ferri, P. H.; Phillipson, J. D.; Paine, A.; Croft, S. L.; Phytochemistry 2000, 55, 589.

12. Matsuda, N.; Kikuchi, M.; Chem. Pharm. Bull. 1996, 44, 1676.

13. Lee, J.; Seo, E. K.; Jang, D. S.; Ha, T. J.; Kim, J. P.; Nam, J. W.; Bae, G.; Lee, Y. M.; Yang, M. S.; Kim, J. S.; Chem. Pharm. Bull. 2009, 57, 298.

14. Barata, L. E.; Baker, P. M.; Gottlieb, O. R.; Rùveda, E. A.; Phytochemistry 1978, 17, 783.

15. Cavalcante, S. H.; Yoshida, M.; Gottlieb, O. R.; Phytochemistry 1985, 24, 1051.

16. Fukagawa, N.; Ishizu, A.; J. Wood Chem. Technol. 1991, 11, 263.

17. Yoshikawa, M.; Morikawa, T.; Xu, F.; Ando, S.; Matsuda, H.; Heterocycles 2003, 60, 1787.

18. Matsuda, N.; Kikuchi, M.; Chem. Pharm. Bull. 1996, 44, 1676.

19. Zhang, X. J.; Yang, G. Y.; Wang, R. R.; Pu, J. X.; Sun, H. D.; Xiao, W. L.; Zheng, Y. T.; Chem. Biodiversity 2010, 7, 2692.

20. Pu, J. X.; Yang, L. M.; Xiao, W. L.; Li, R. T.; Lei, C.; Gao, X. M.; Huang, S. X.; Li, S. H.; Zheng, Y. T.; Huang, H.; Sun, H. D.; Phytochemistry 2008, 69, 1266.

21. Darke, P. L.; Huff, J. R.; Adv. Pharmacol. 1994, 25, 399. 
22. Hahm, J. C.; Lee, I. K.; Kang, W. K.; Kim, S. U.; Ahn, Y. J.; Planta Med. 2005, 71, 464.

23. Amblard, F.; Govindarajan, B.; Lefkove, B.; Rapp, K. L.; Detorio, M.; Arbiser, J. L.; Schinazi, R. F.; Bioorg. Med. Chem. Lett. 2007, 17, 4428.
24. Mosmann, T.; J. Immunol. Methods 1983, 65, 55.

Submitted: February 12, 2012

Published online: June 19, 2012 


\section{8-O-4'-Neolignans from Flower Buds of Magnolia fargesii and their Biological Activities}

\section{Xuemei Gao, ${ }^{a}$ Yanqiong Shen, ${ }^{a}$ Liying Yang, ${ }^{a, b}$ Lidang Shu, ${ }^{a}$ Ganpeng $L i^{*, a, b}$ and Qiu-Fen Hu ${ }^{*, a}$}

${ }^{a}$ Key Laboratory of Chemistry in Ethnic Medicinal Resources, State Ethnic Affairs Commission \& Ministry of Education, Yunnan University of Nationalities, Kunming 650031, P. R. China

${ }^{b}$ Key Laboratory of Tobacco Chemistry of Yunnan Province, Yunnan Academy of Tobacco Science, Kunming 650106, P. R. China
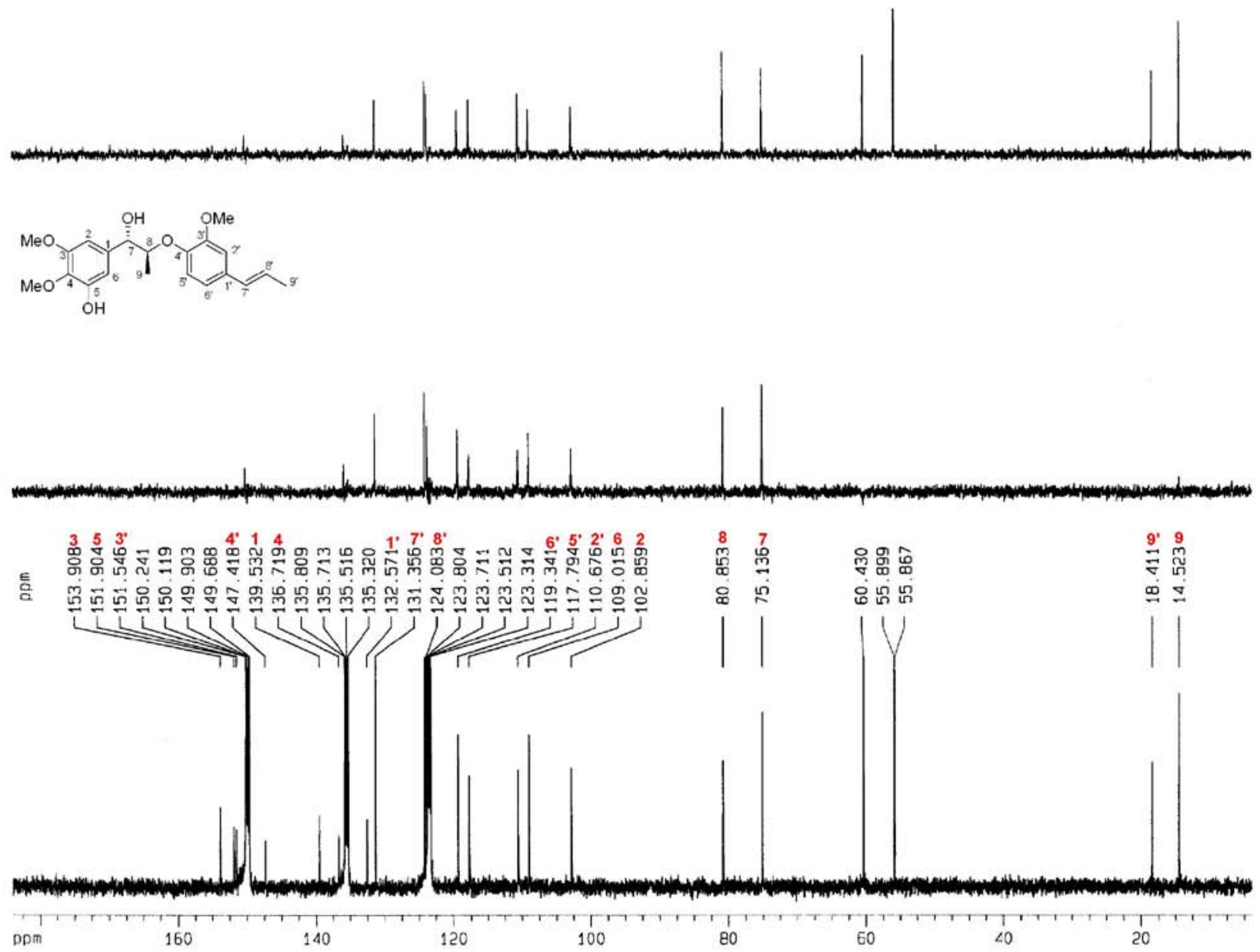

Figure S1. ${ }^{13} \mathrm{C}$ NMR and DEPT spectra of fargesiphenol A (1).

*e-mail: huqiufena@yahoo.com, ganpeng_li@ sina.com 


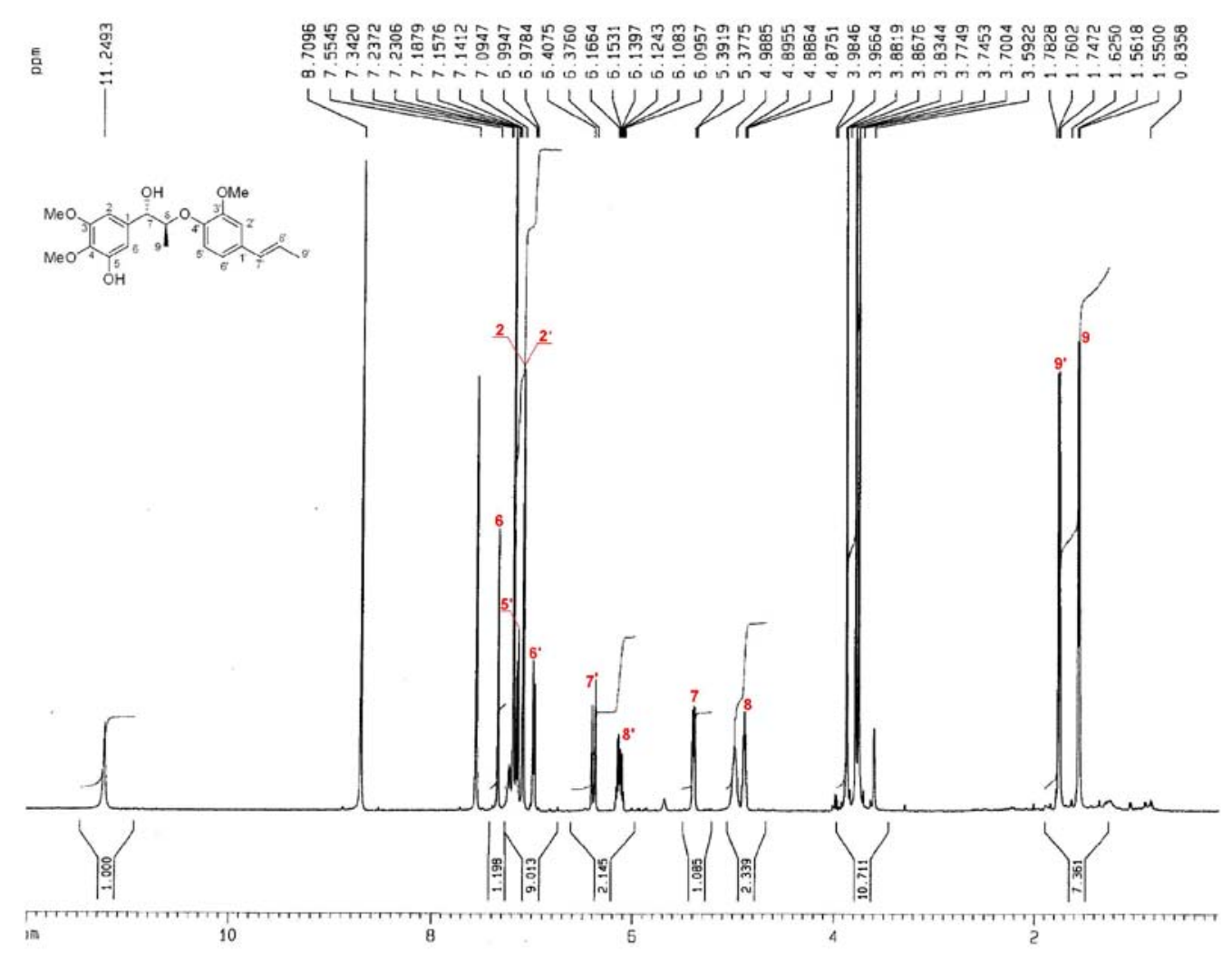

Figure S2. ${ }^{1} \mathrm{H}$ NMR spectra of fargesiphenol A (1).

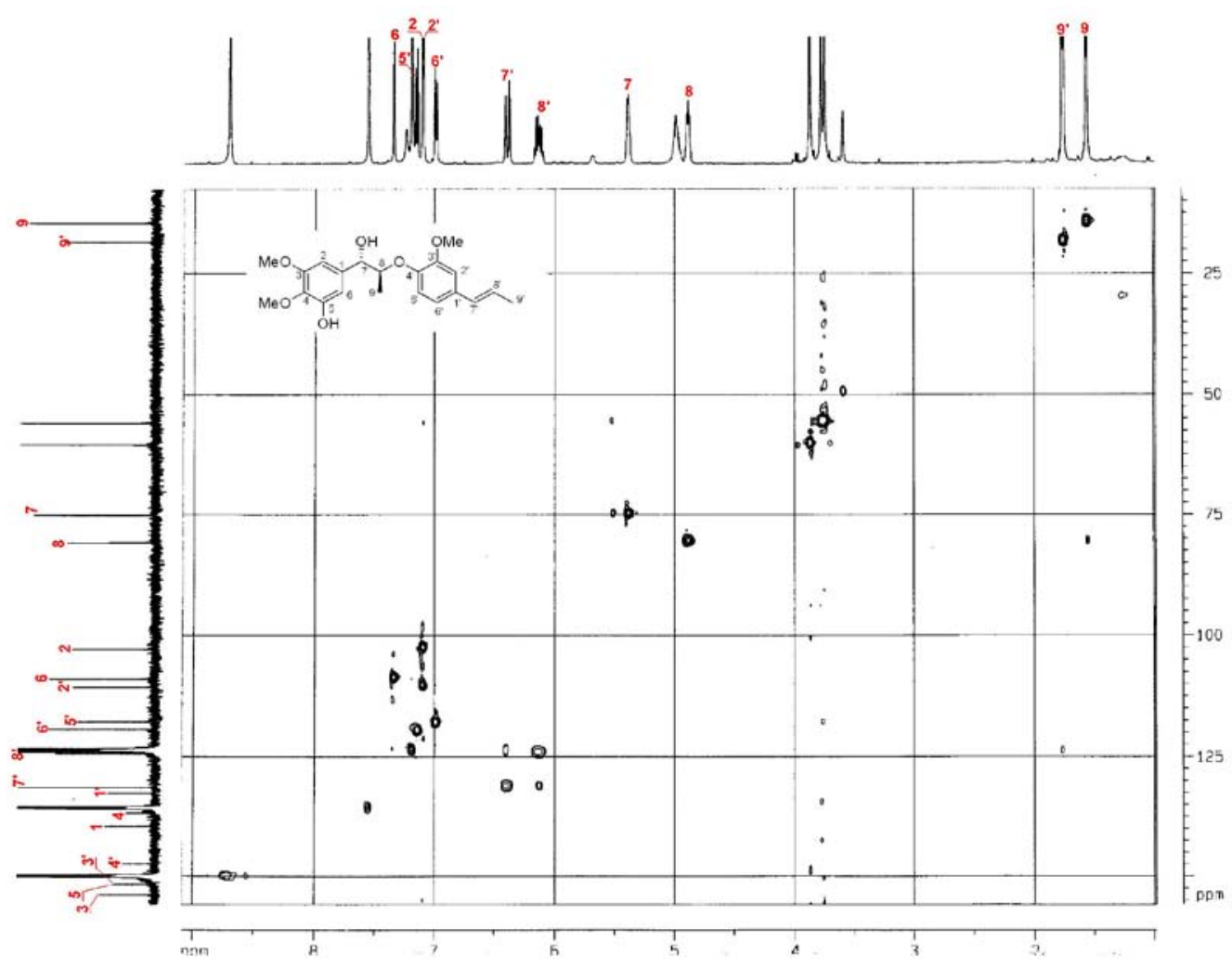

Figure S3. HSQC spectra of fargesiphenol A (1). 


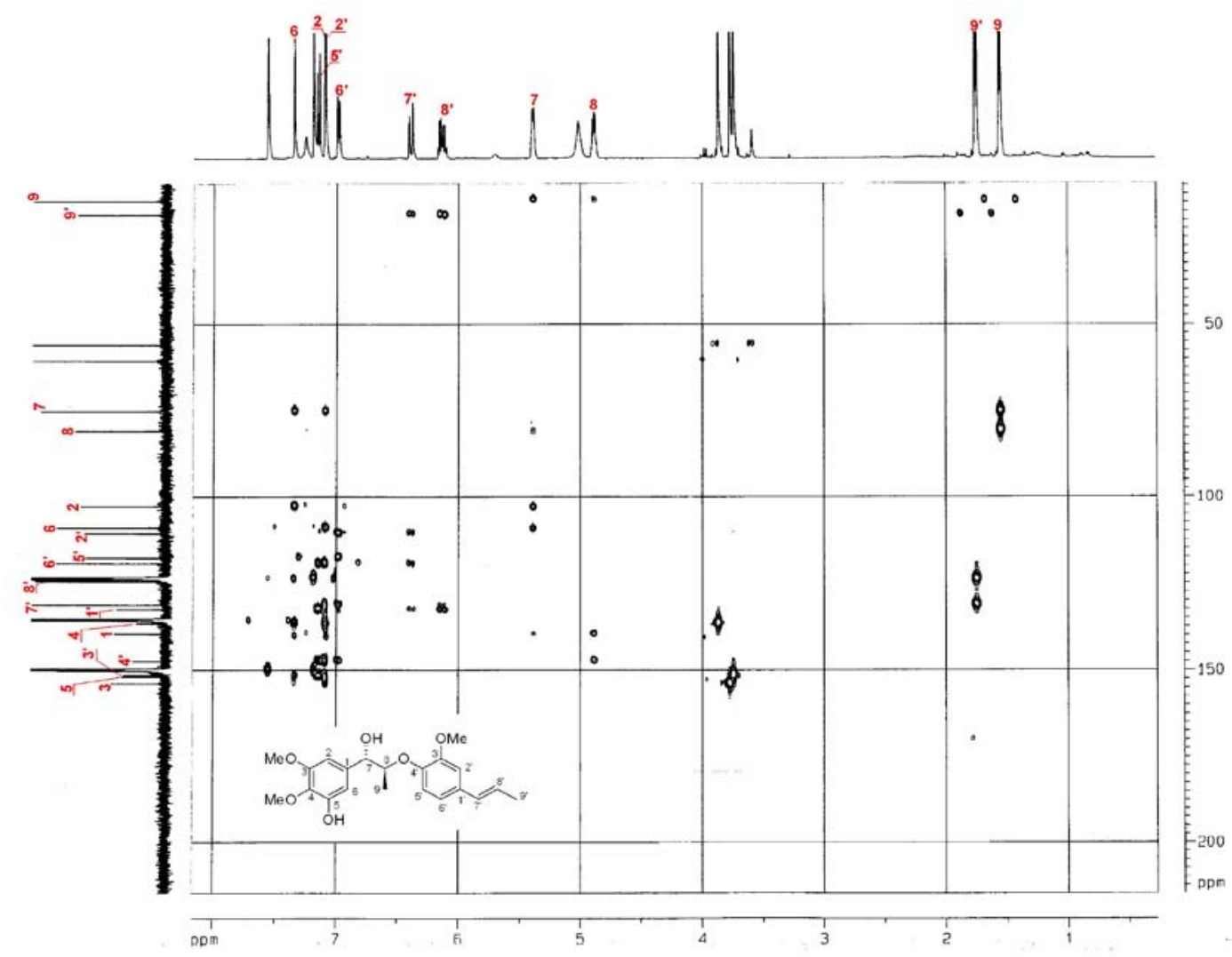

Figure S4. HMBC spectra of fargesiphenol A (1).

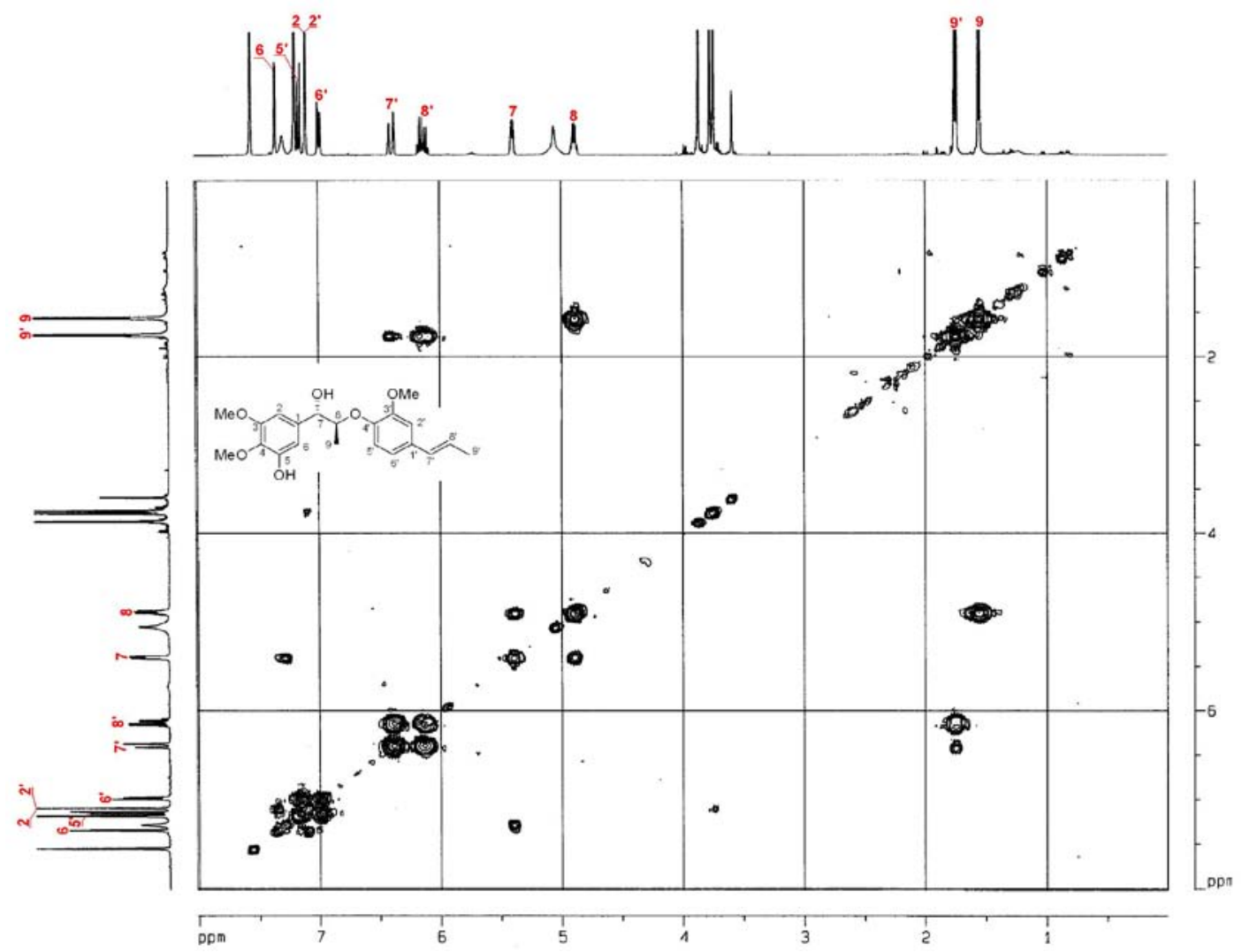

Figure S5. ${ }^{1} \mathrm{H}-{ }^{-1} \mathrm{H}$ COSY spectra of fargesiphenol A (1). 


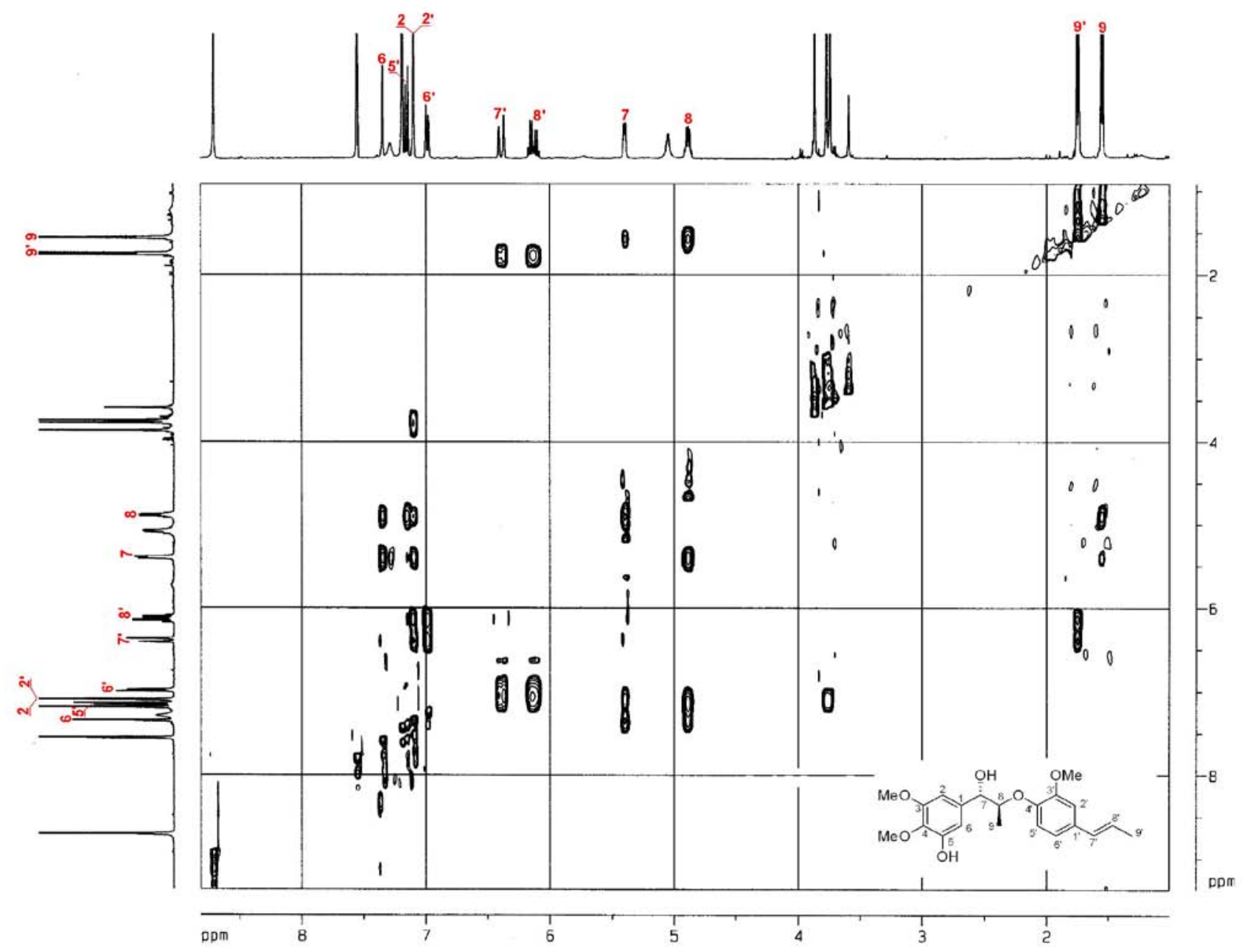

Figure S6. ROESY spectra of fargesiphenol A (1).

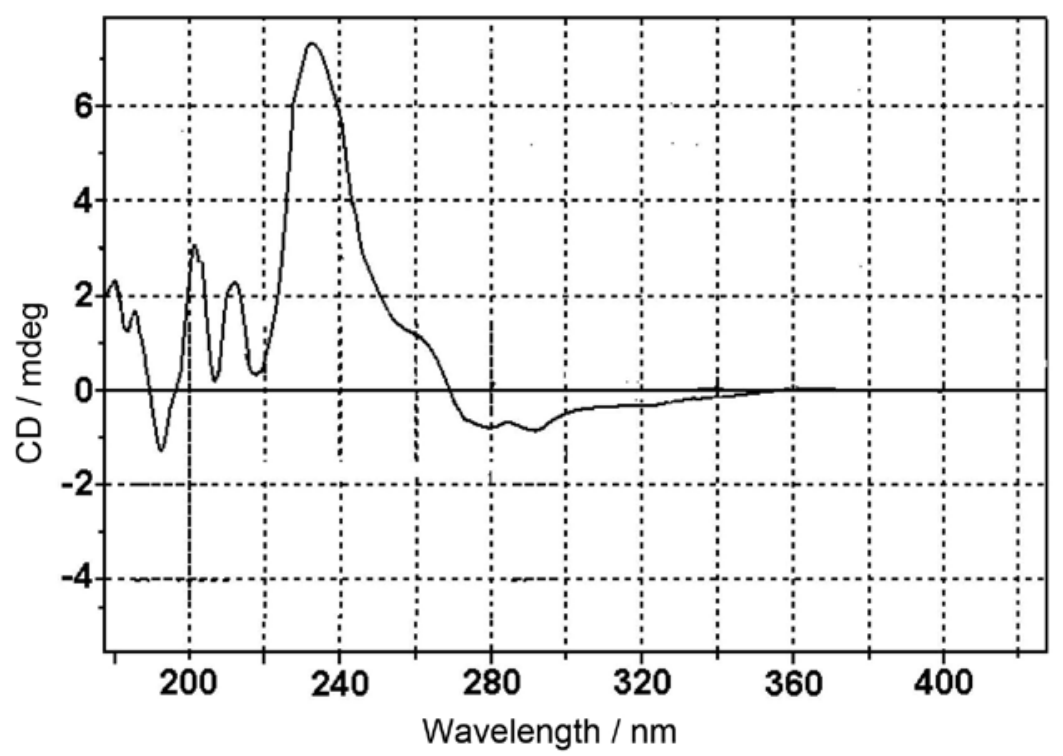

Figure S7. CD spectra of fargesiphenol A (1). 
Vol. 23, No. 7, 2012

Gao et al.

SF

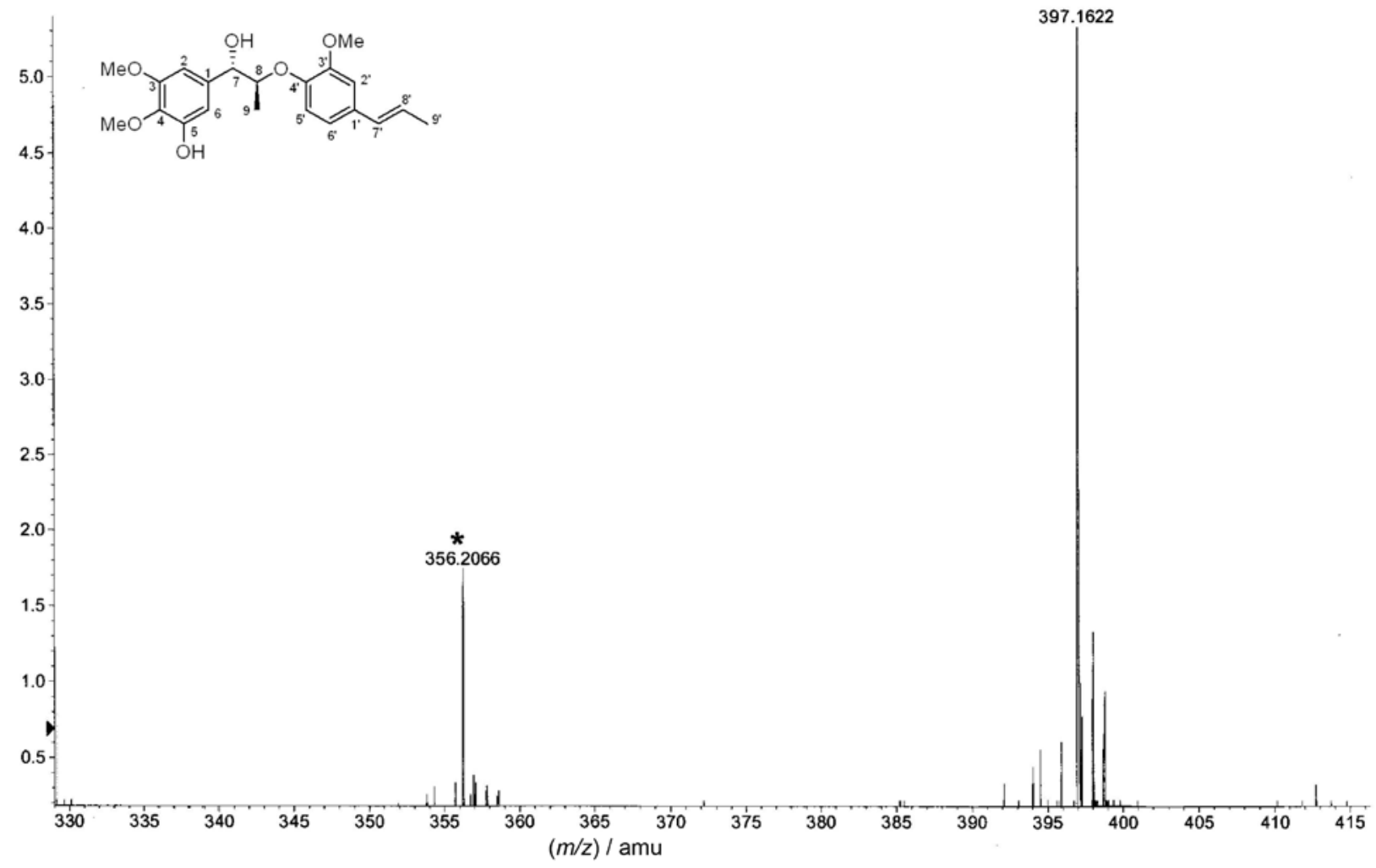

Figure S8. HRESIMS spectra of fargesiphenol A (1).
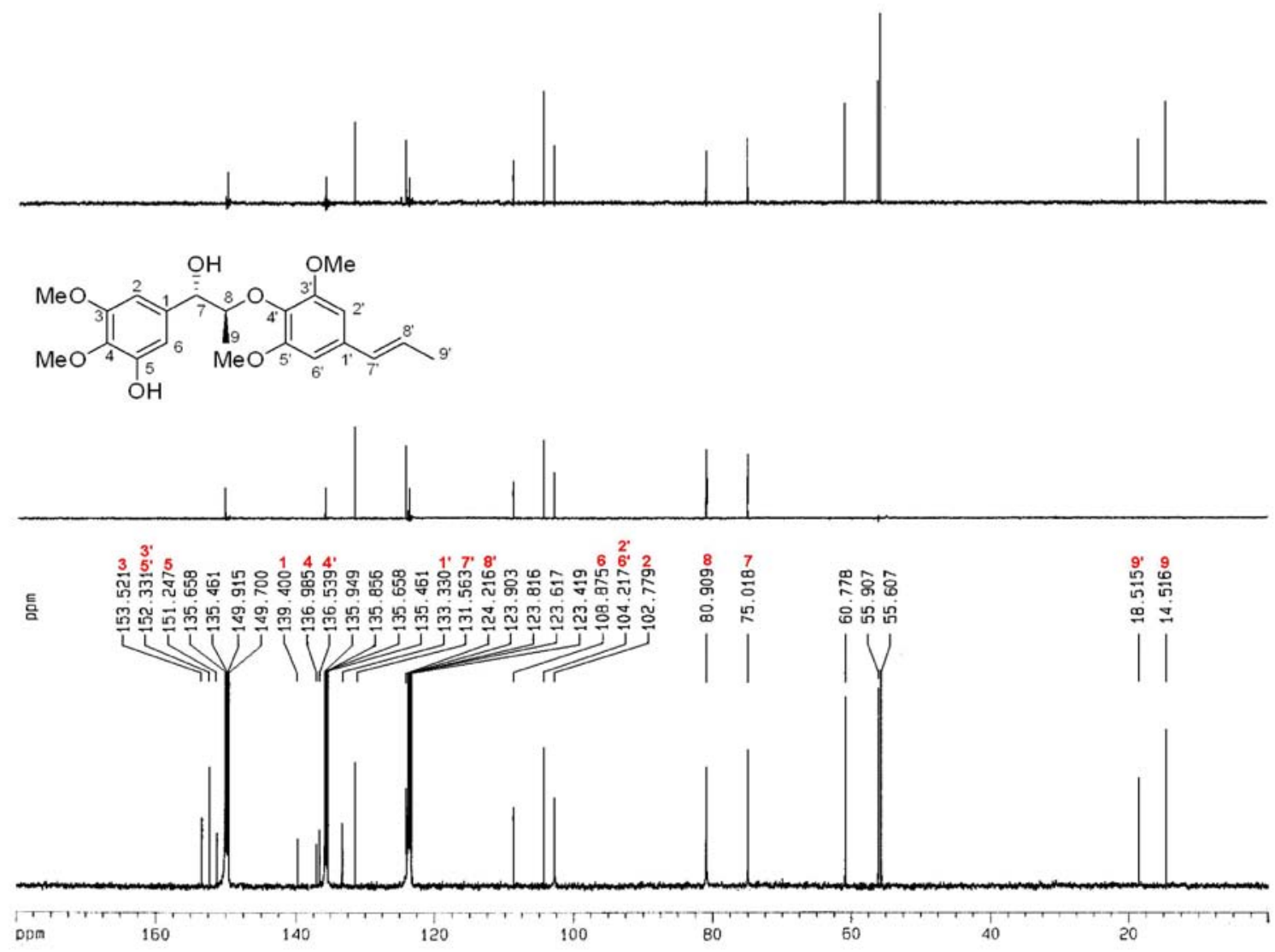

Figure S9. ${ }^{13} \mathrm{C}$ NMR and and DEPT spectra of fargesiphenol B (2). 

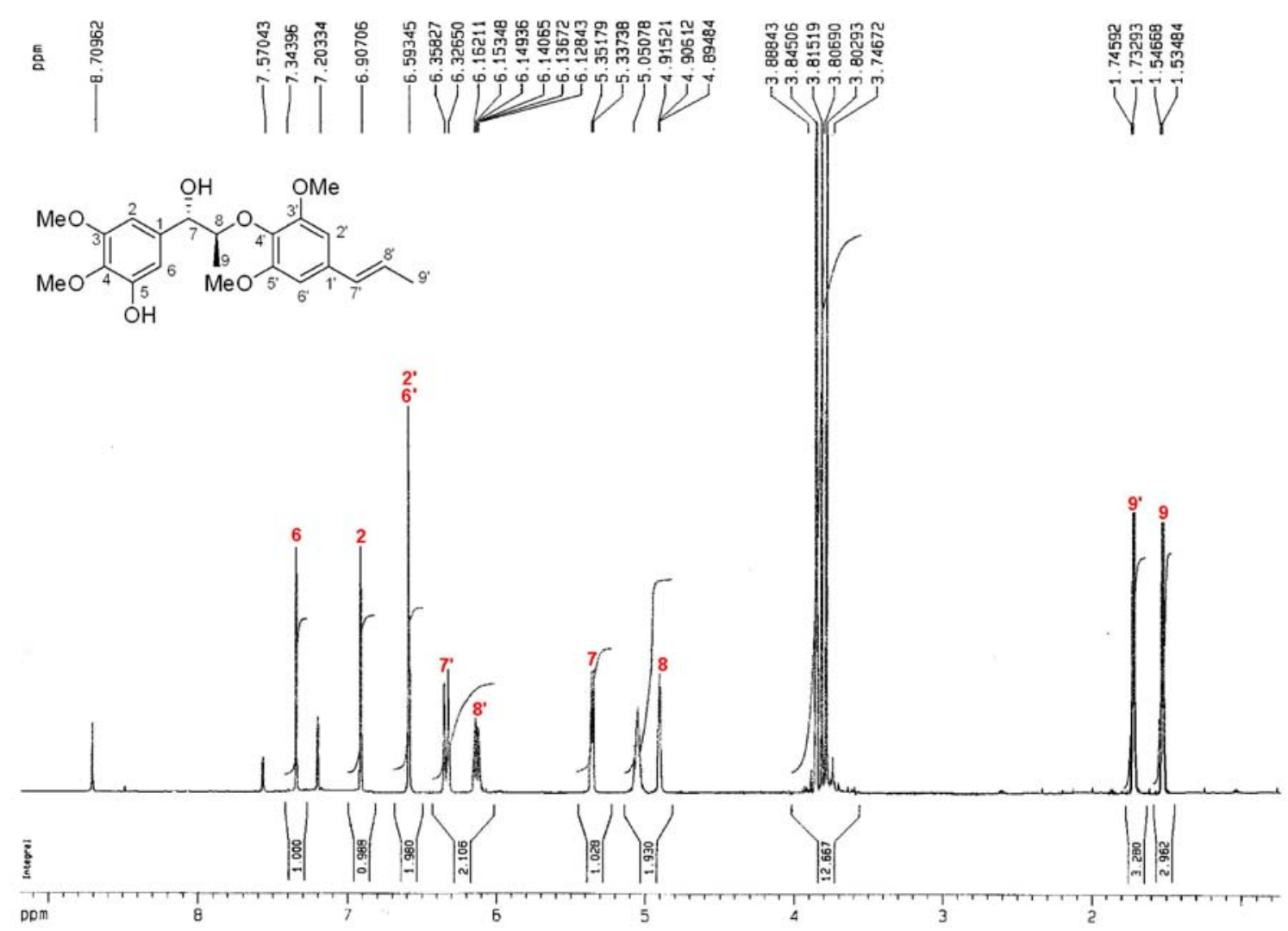

Figure S10. ${ }^{1} \mathrm{H}$ NMR spectra of fargesiphenol B (2).

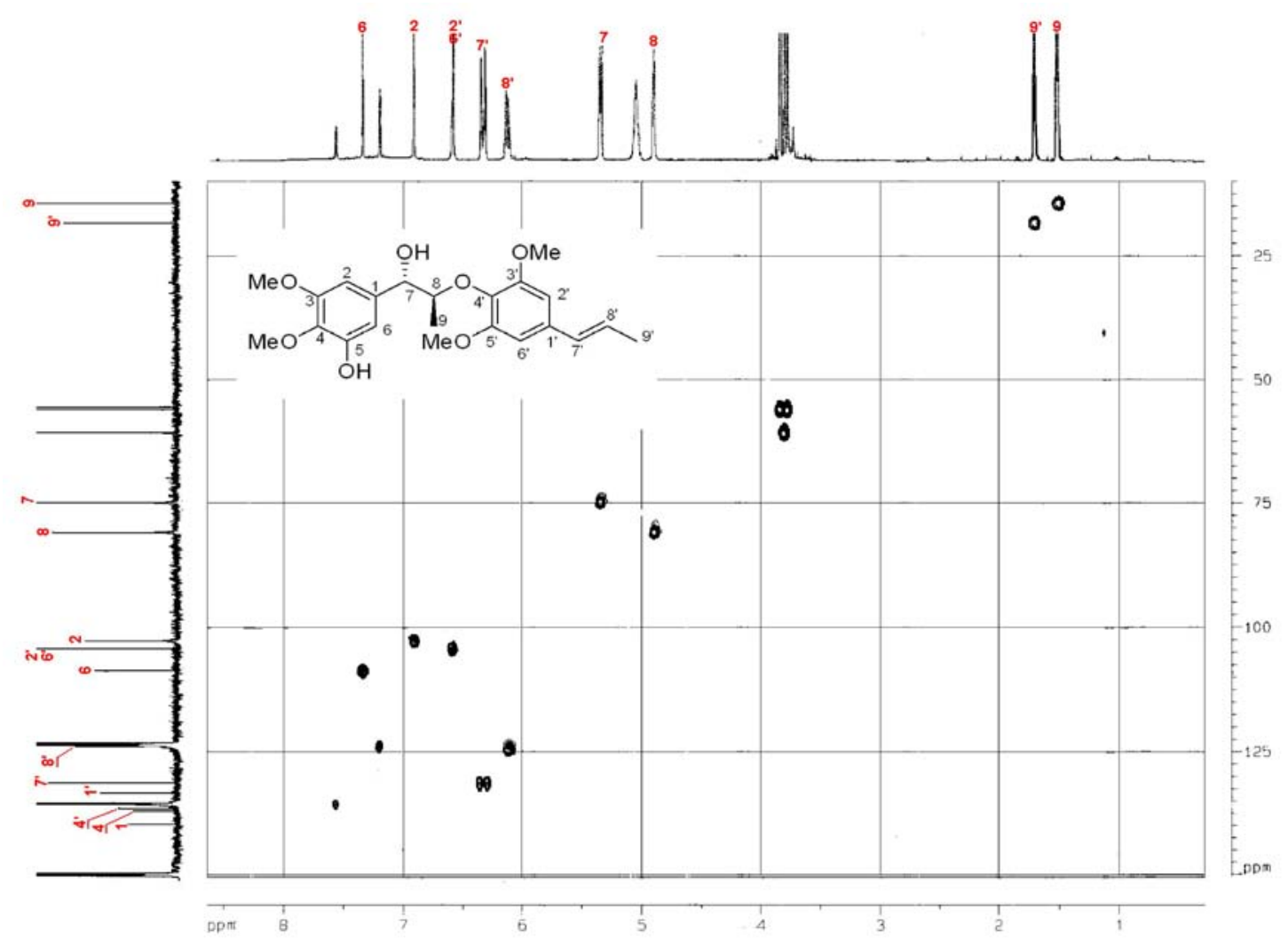

Figure S11. HSQC spectra of fargesiphenol B (2). 


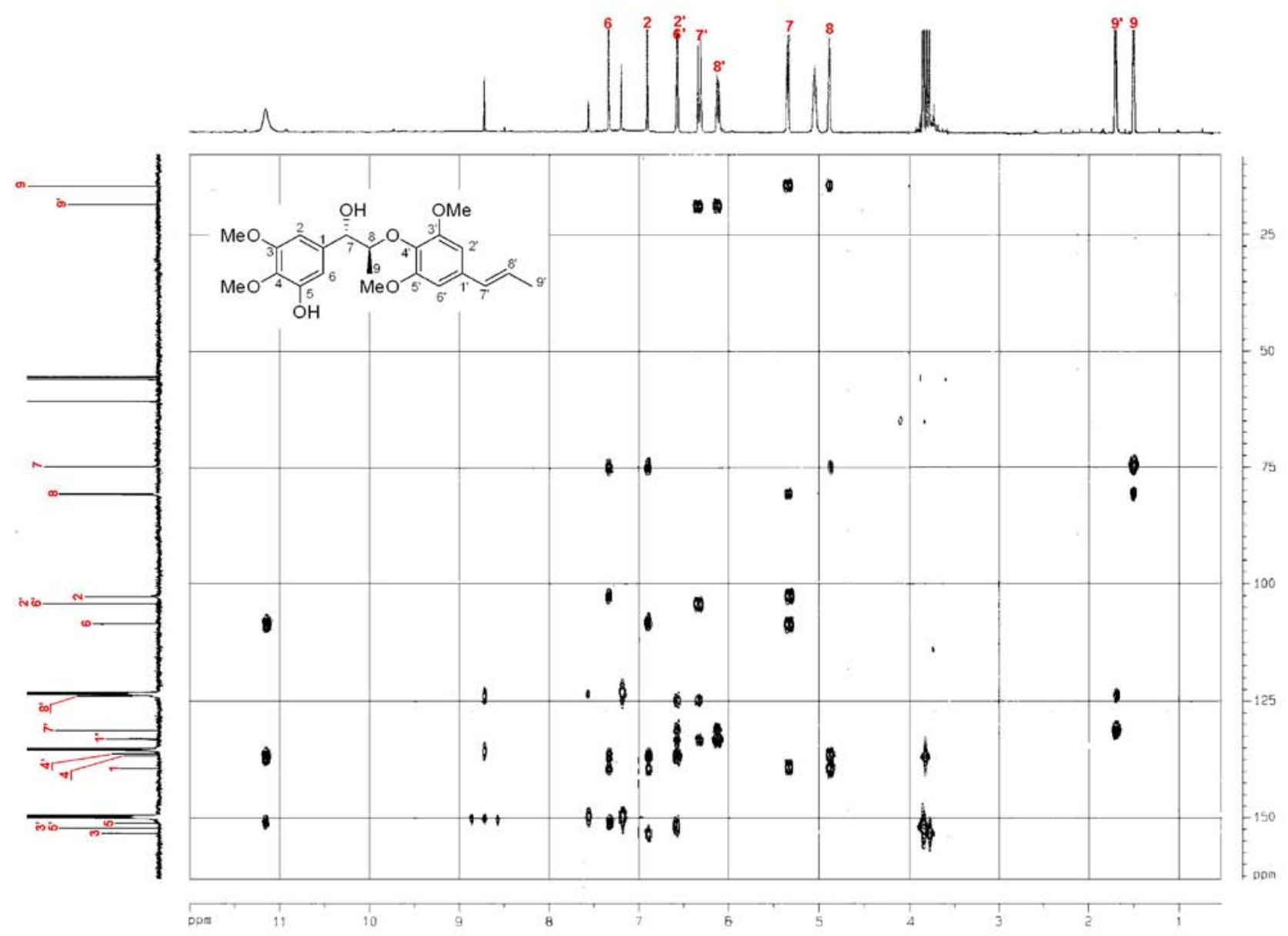

Figure S12. HMBC spectra of fargesiphenol B (2).

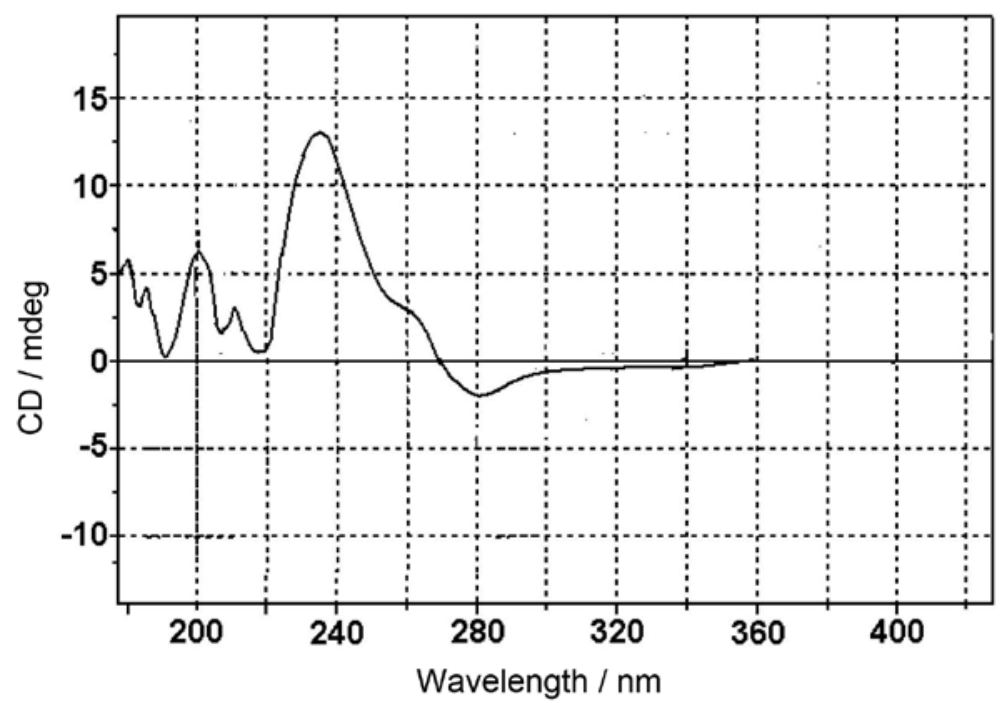

Figure S13. CD spectra of fargesiphenol B (2). 

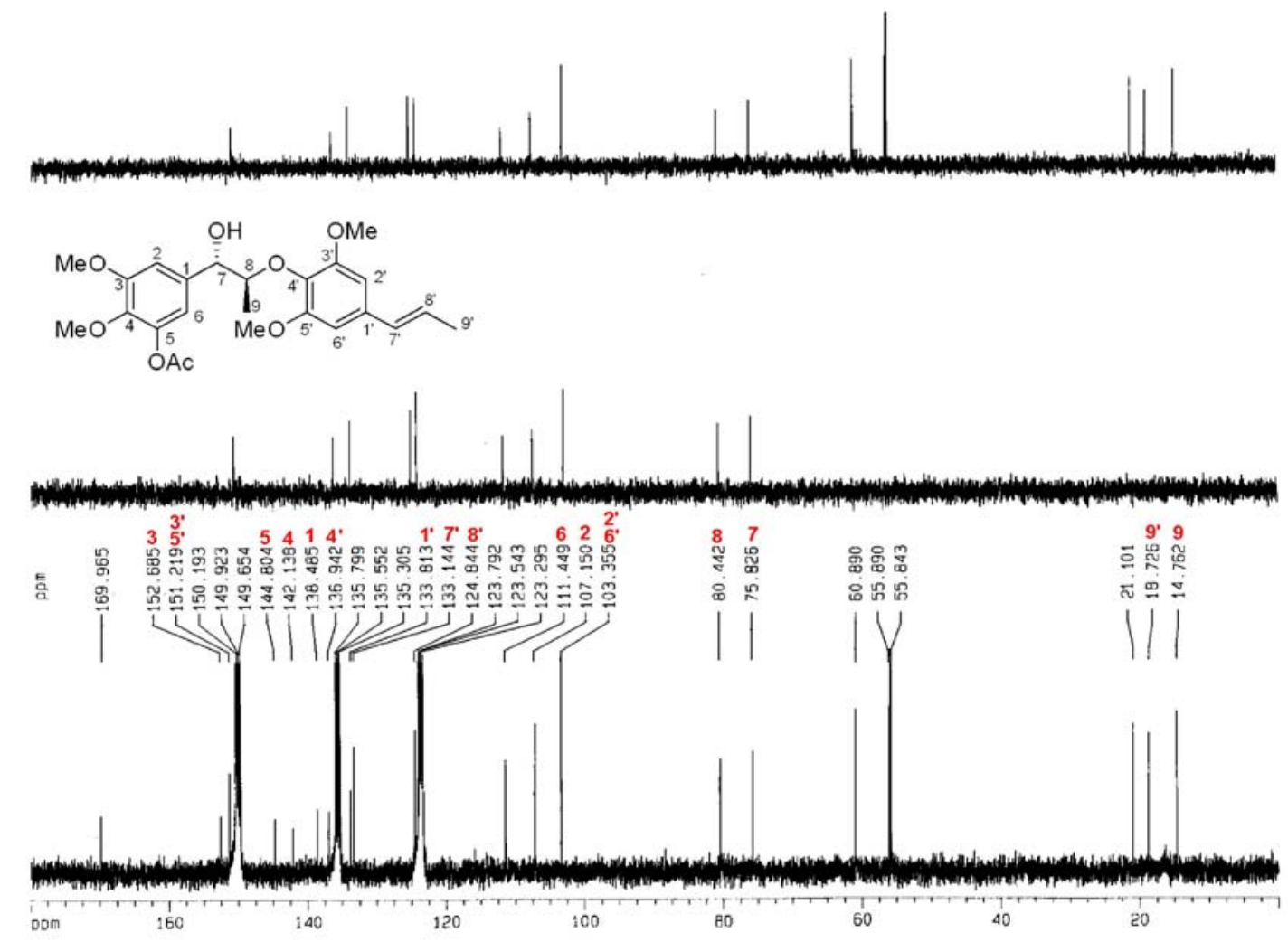

Figure S14. ${ }^{13} \mathrm{C}$ NMR and and DEPT spectra of fargesiphenol C (3).

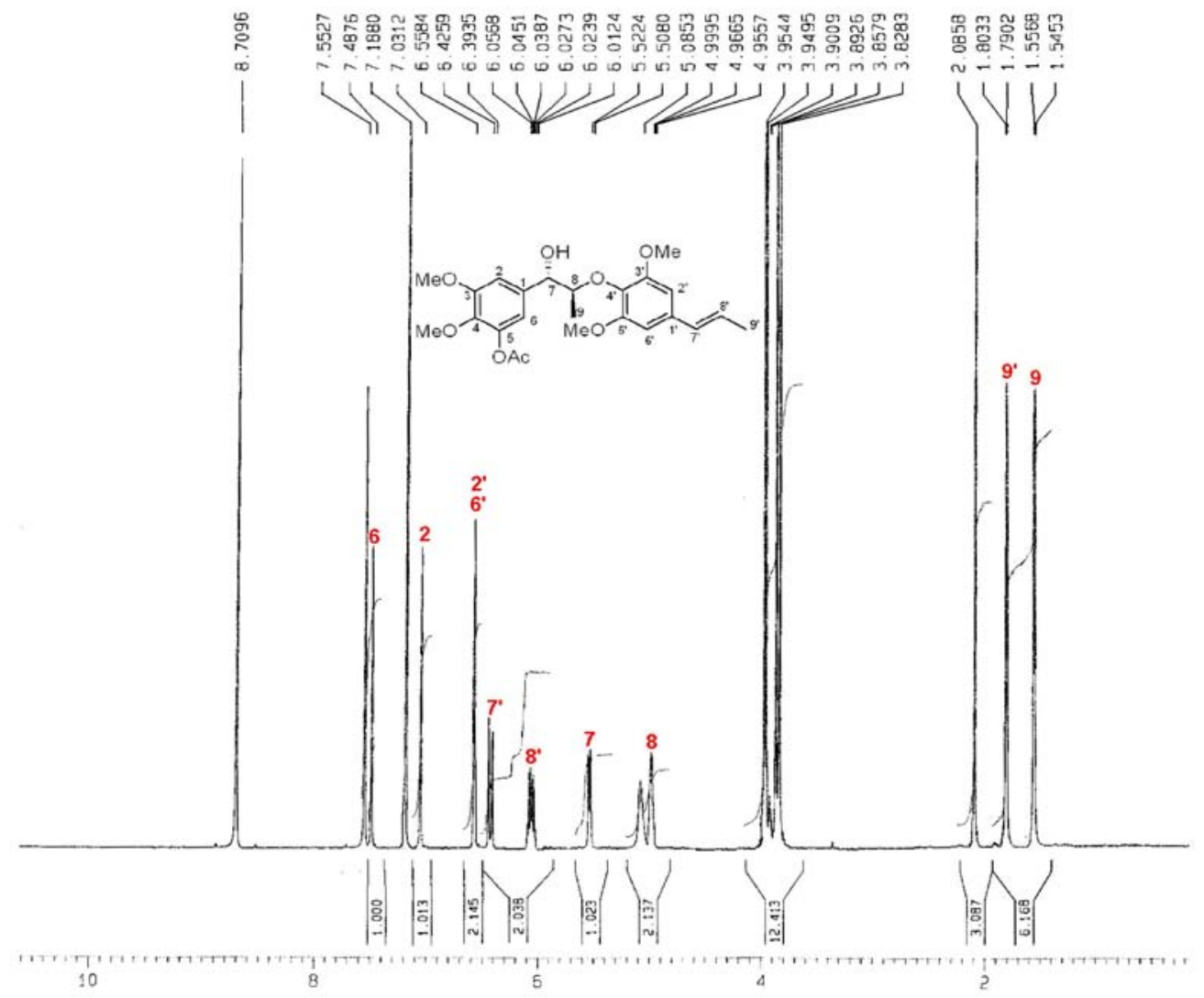

Figure S15. ${ }^{1} \mathrm{H}$ NMR spectra of fargesiphenol C (3). 
Vol. 23, No. 7, 2012

Gao et al.

S9

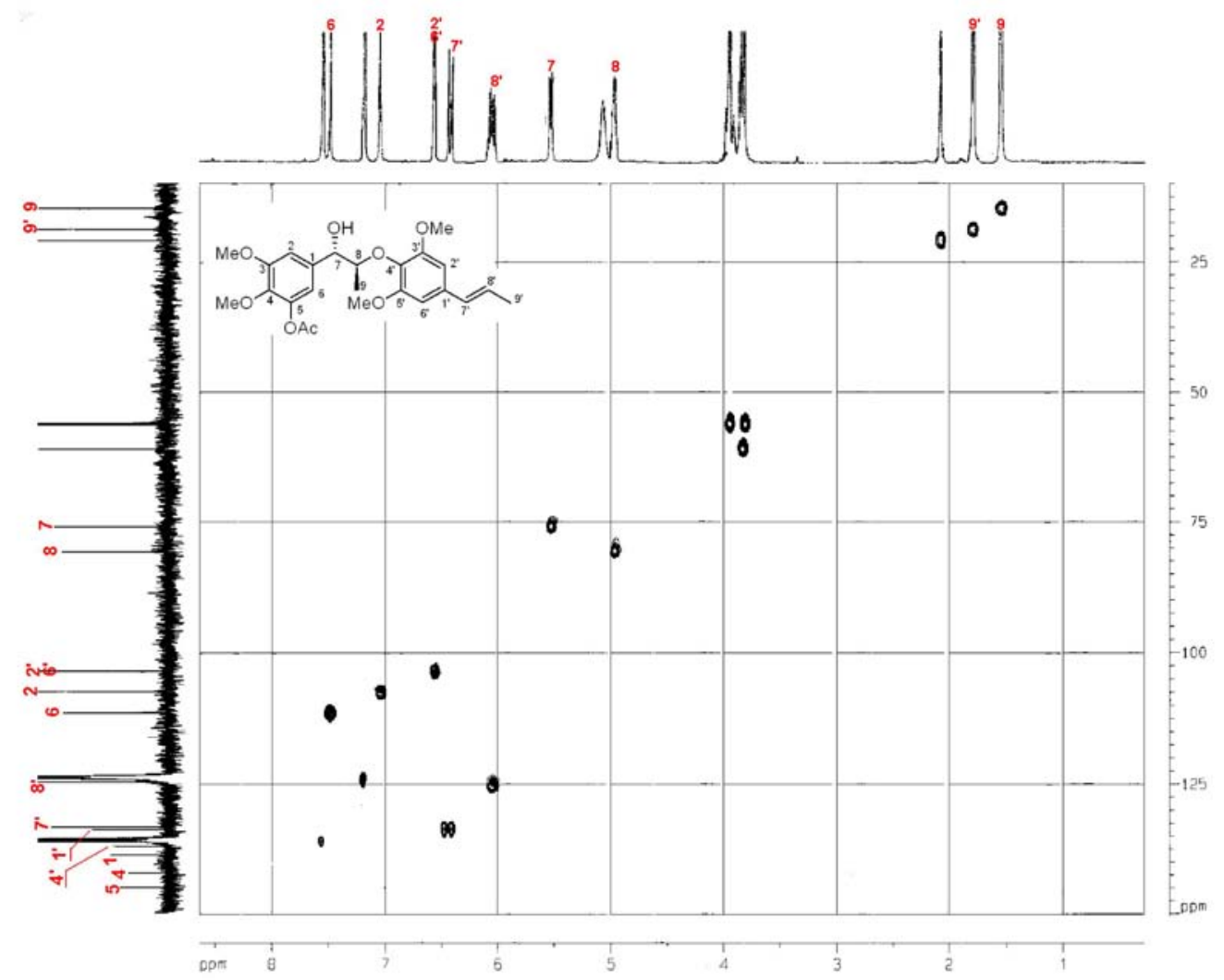

Figure S16. HSQC spectra of fargesiphenol C (3).

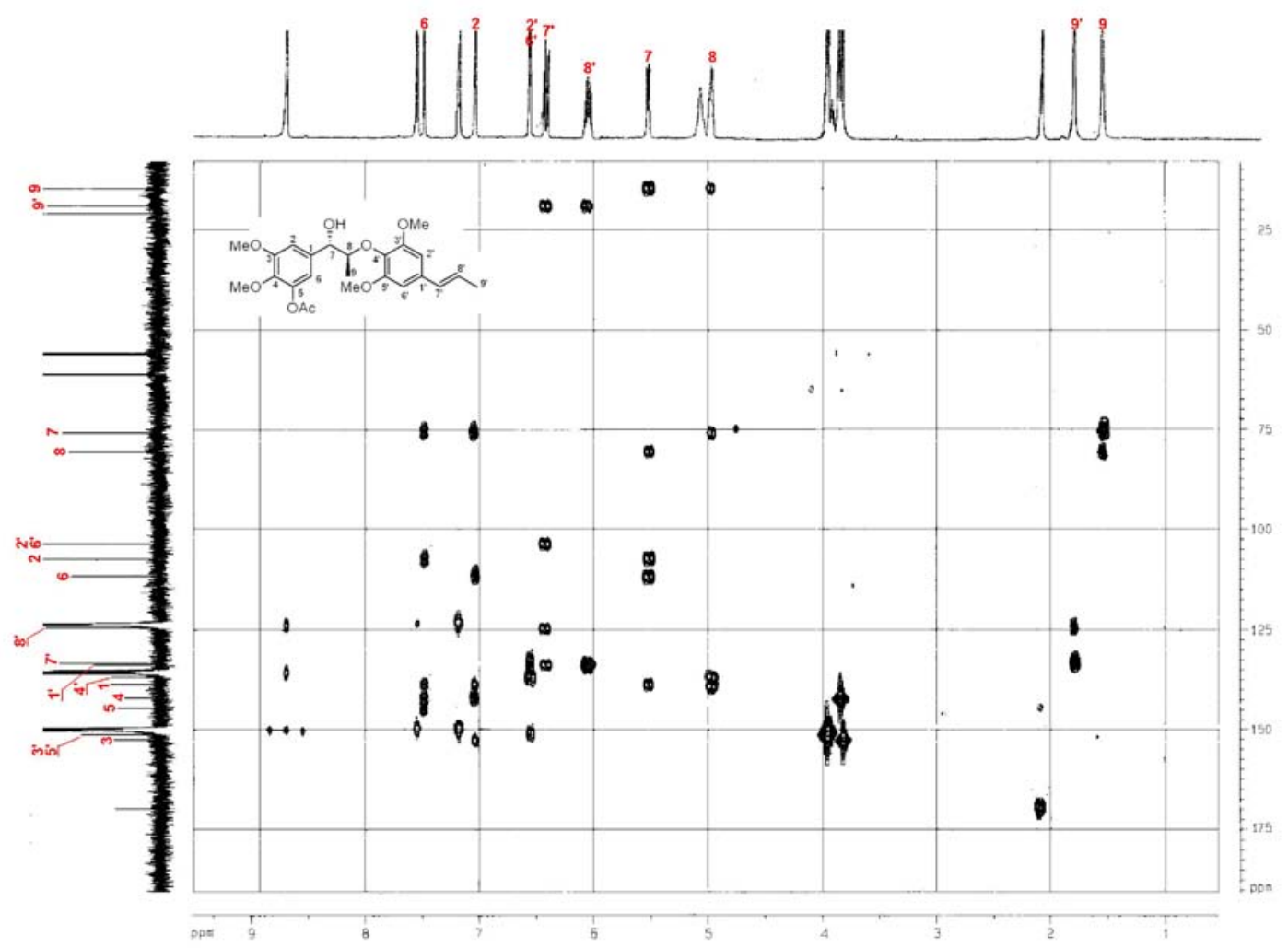

Figure S17. HMBC spectra of fargesiphenol C (3). 


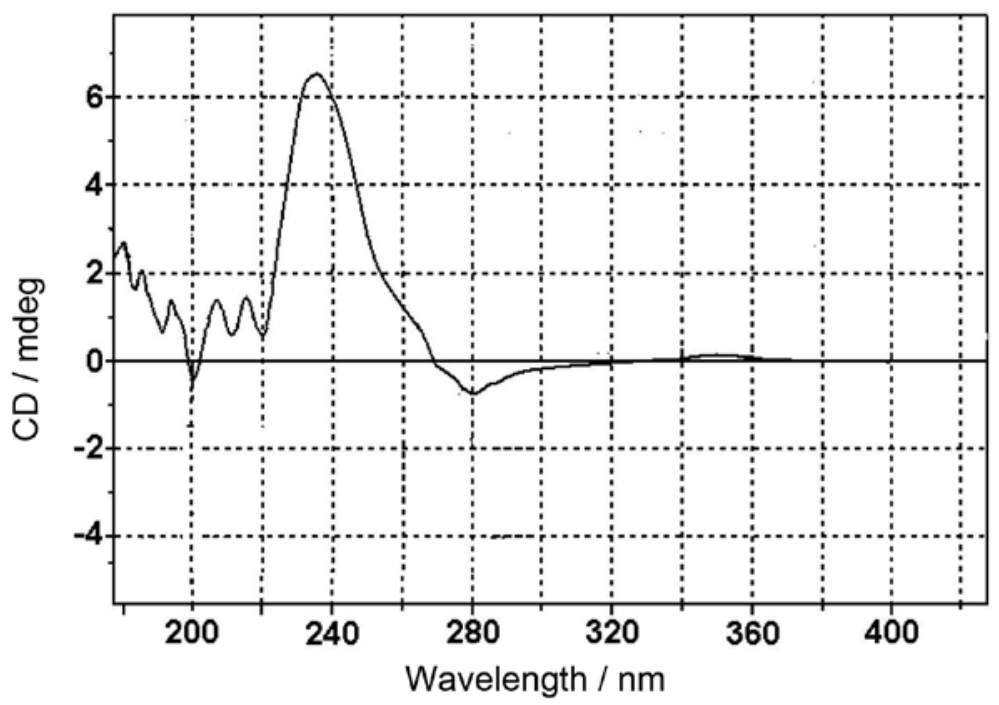

Figure S18. CD spectra of fargesiphenol C (3). 